\title{
PELATIHAN PEMBUATAN PROPERTI TARI DENGAN MEMANFAATKAN BARANG BEKAS BAGI GURU DI SDN 47 KOTA BENGKULU
}

\author{
Hasnawati, Dwi Anggraini, Pebrian Tarmizi \\ FKIP-PGSD-Universitas Bengkulu \\ Jl. Wr. Supratman, Kandang Limun, Muara Bangka Hulu, \\ Kota Bengkulu, Bengkulu 38371 \\ dwianggraini@unib.ac.id
}

\begin{abstract}
ABSTRAK
Kegiatan pelatihan pembuatan properti tari ini bertujuan untuk meningkatkan pengetahuan dan keterampilan guru SDN 47 dalam membuat properti tari dengan memanfaatkan barang bekas sebagai upaya untuk mengurangi limbah sampah di lingkungan, khususnya lingkungan SD Negeri 47 yang berada di sekitar pemukiman penduduk. Sasaran kegiatan ini adalah guru-guru yang berjumlah 9 orang. Metode yang digunakan adalah pelatihan yang terdiri dari tiga tahapan, yaitu tahap persiapan, pelaksanaan dan evaluasi. Pada kegiatan ini, barang bekas yang dominan digunakan yaitu kardus yang dibuat menjadi properti bertema hewan dan tumbuhan. Guru dibagi menjadi dua kelompok, yaitu kelompok pertama membuat properti tema hewan (lebah) dan kelompok kedua bertema tumbuhan (bunga). Guru membuat properti yang berbeda dari contoh tim PPM dengan detail properti yang lebih kompleks. Simpulan dari kegiatan ini yaitu guru dapat memiliki keterampilan dalam membuat properti tari dengan memanfaatkan barang bekas.
\end{abstract}

Kata Kunci: Properti; Tari; Barang Bekas 


\section{Jurnal Batoboh, Vol 4 , No 1, Maret 2019 \\ Hasnawati, Dwi Anggraini, Pebrian Tarmizi}

\section{PENDAHULUAN}

Sekolah yang akan dijadikan mitra pada kegiatan Pengabdian Pada Masyarakat (PPM) ini adalah SDN 47 Kota Bengkulu. Sekolah ini berada di Pesisir Pantai Panjang Bengkulu di kecamatan Teluk Segara Kota Bengkulu. Sekolah ini termasuk pada sekolah yang berprestasi cukup, artinya prestasi yang diraih masih sedikit dan sekolah ini jarang sekali dijadikan mitra PPL.

Sekolah ini tidak termasuk pada sekolah yang tergolong bersih. Lingkungan di sekitar sekolah masih terdapat sampahsampah berserakan. Hal ini dikarenakan sekolah berada di tengah pemukiman penduduk yang bisa dikatakan kumuh. Melihat kondisi ini maka perlu adanya satu solusi agar lingkungan yang kumuh tidak membawa dampak negatif pada siswa baik dari kesehatan maupun sikap peduli lingkungan. Maka perlu upaya untuk membuat dampak negatif tersebut menjadi positif agar bermanfaat bagi pihak sekolah. Salah satunya yaitu dengan memanfaatkan barang bekas (sampah) menjadi hal-hal yang bermanfaat, misalnya properti dalam pembelajaran tari.

Dalam kurikulum KTSP, mata pelajaran Seni Budaya dan Keterampilan
(SBK) yang harus diajarkan kepada siswa meliputi seni rupa, tari, musik, dan keterampilan. Namun demikian, pembelajaran seni SDN 47 Kota Bengkulu terkadang tidak dilaksanakan dan dianggap tidak terlalu penting karena tidak diujikan dalam ujian nasional. Hal ini dikarenakan sekolah ini tidak memiliki guru khusus bidang seni. Oleh sebab itu, guru kelas bertanggungjawab sepenuhnya atas terlaksananya seluruh mata pelajaran yang menjadi tuntutan kurikulum.

Dalam pembelajaran seni, khususnya seni tari membutuhkan properti sebagai pendukung tari. Apalagi jika melaksanakan pembelajaran seni tari bertema (bercerita). Kedudukan properti menjadi sangat penting. Properti tari tidak harus selalu dibeli. Properti tari dapat dibuat dengan memanfaatkan barang bekas, contohnya properti tari bertema hewan. Misalkan hewan yang dimaksud adalah kupu-kupu, maka guru bahkan bersama dengan siswa dapat mendesain dan membuat sayap kupu-kupu menggunakan kardus-kardus yang sudah tidak terpakai, antena dengan sedotan dan lain sebagainya. Properti ini dapat dimanfaatkan sekaligus sebagai kostum tari. Dengan demikian secara tidak langsung dapat membantu mengurangi jumlah sampah yang ada di lingkungan 


\section{Jurnal Batoboh, Vol 4 , No 1, Maret 2019 \\ Hasnawati, Dwi Anggraini, Pebrian Tarmizi}

kita. Selain itu keterlibatan siswa dalam membuat properti dapat memberikan pengalaman estetik bagi siswa. Hal ini sejalan dengan pendapat Herbert Read dalam Kusumastuti (2009: 103) yang mengatakan bahwa pendidikan seni lebih berdimensikan sebagai media pendidikan yang memberikan serangkaian pengalaman estetik yang sangat besar pengaruhnya bagi perkembangan jiwa anak.

$$
\text { Menurut Hamzah (2013) upaya }
$$
pengelolaan lingkungan mencakup aspek pemanfaatan, pengaturan, pemilihan, pemulihan, pengendalian, pembinaan, serta upaya pelestarian lingkungan hidup yang dilaksanakan secara integratif. Pemanfaatan sampah salah satunya yaitu dengan mengolah sampah menjadi barang tepat guna, yaitu membuat properti tari. Keterlibatan siswa dalam membuat properti tari menggunakan barang bekas berimbas baik bagi siswa, yaitu mereka akan menyadari bahwa barang-barang yang sudah tidak terpakai masih dapat diolah dan digunakan untuk kebutuhan lain yang lebih bermanfaat, sehingga sikap peduli lingkungan terinternalisasi ke dalam diri siswa secara natural.

Berdasarkan permasalahan di atas, maka dirasa sangat penting untuk diadakannya pelatihan membuat properti tari dengan memanfaatkan barang bekas bagi guru di SDN 47 Kota Bengkulu. Mengingat manfaat yang didapatkan melalui pelatihan ini sangat besar, maka diharapkan pelatihan dapat segera dilaksanakan.

\section{Hal | 35}

\section{Metode}

Sasaran kegiatan ini adalah guru SD Negeri 47 Kota Bengkulu yang berjumlah 9 orang. Metode kegiatan PPM yang dilaksanakan adalah sebagai berikut.

1. Tahap Persiapan

Adapun yang dilakukan pada tahap persiapan adalah berikut ini.

a. Survey ke lokasi pelaksanaan PPM.

b. Koordinasi dengan pihak sekolah untuk pelaksanaan kegiatan.

c. Pendataan peserta pelatihan.

d. Pembuatan jadwal pelatihan.

e. Menyiapkan materi, instrumen, alat serta bahan pelatihan.

2. Tahap Pelaksanaan

a. Menyampaikan materi tentang seni tari, manfaat dan kedudukan properti di dalam tari.

b. Praktik membuat properti tari dibimbing oleh tim PPM.

c. Pada saat penyampaian materi dan praktik, tim PPM melakukan 


\section{Jurnal Batoboh, Vol 4 , No 1, Maret 2019 \\ Hasnawati, Dwi Anggraini, Pebrian Tarmizi}

observasi untuk mendapatkan data atau pencapaian peserta PPM selama mengikuti pelatihan.

3. Tahap Evaluasi

a. Mengolah data observasi dan wawancara

b. Menganalisa data dan menarik kesimpulan

Hasil

Kegiatan PPM ini dilaksanakan pada hari Sabtu tanggal 6 Oktober 2018 di SD Negeri 47 Kota Bengkulu yang beralamat di Kelurahan Pasar Baru Kecamatan Teluk Segara. Sasaran kegiatan ini adalah semua guru yang berjumlah 9 (sembilan) orang.

Tahapan pelatihan pembuatan properti tari dengan memanfaatkan barang bekas yaitu pemberian materi dan praktik membuat properti tari. Materi yang disampaikan yaitu tentang wawasan seni tari pada umumnya, kedudukan properti dalam tari, dan properti dari barang bekas. Setelah pemberian materi dilakukan tanya jawab seputar materi yang diberikan.

Tim PPM memberikan pelatihan berupa praktik membuat properti tari dengan memanfaatkan barang bekas. Properti yang dibuat dibatasi dengan tema yaitu tema hewan dan tumbuhan. Barang bekas yang menjadi bahan utama yaitu kardus. Adapun bahan tambahan untuk memperindah kardus tersebut adalah karton berwarna, kertas origami, lem tembak, kawat, cat air, bando polos, tali plastik, karet rok dan spidol. Sedangkan alat yang digunakan yaitu gunting, cutter, dan lem tembak.

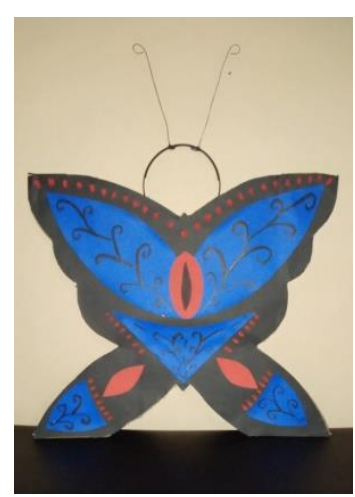

Gambar 1.

Contoh Properti tema hewan oleh tim PPM

(Dokumentasi oleh

Dwi Anggraini)

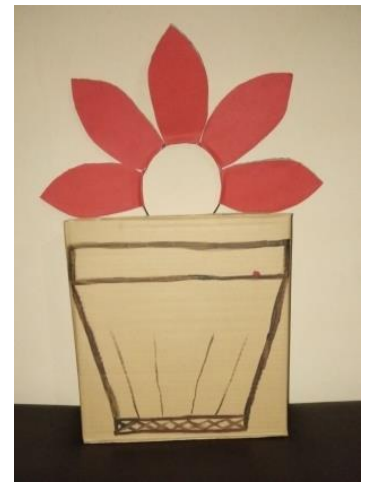

Gambar 2. Contoh properti tumbuhan oleh Tim PPM

(Dokumentasi oleh

Dwi Anggraini)
Guru atau peserta pelatihan dibagi menjadi 2 kelompok yaitu kelompok tumbuhan dan kelompok hewan. Sehingga hasil karya yang dihasilkan berbeda-beda. Pada saat proses pembuatan properti, tim PPM melakukan observasi proses pembuatan dan properti yang dibuat. Adapun hasil observasi yang diperoleh adalah sebagai berikut.

\section{a. Deskripsi Pembuatan Properti Tema}

\section{Hewan}




\section{Jurnal Batoboh, Vol 4 , No 1, Maret 2019 \\ Hasnawati, Dwi Anggraini, Pebrian Tarmizi}

Langkah pertama yang dilakukan yaitu menentukan hewan apa yang akan dibuat. Peserta melakukan diskusi dengan anggota kelompoknya. Kelompok ini memilih hewan kumbang. Kemudian peserta menyiapkan alat dan bahan yang telah disiapkan. Peserta memilih kardus, kawat, bando, karton berwarna orange, kertas origami, cat air, tali plastik warna merah dan karet rok. Sedangkan alat yang dipilih yaitu lem tembak, gunting dan cutter.

Langkah selanjutnya yaitu salah satu peserta membuat pola untuk sayap lebah. Kemudian memotong kardus berpola dengan cutter. Peserta yang lain membuat pola pada karton berwarna dan memisahmisahkan tali plastik dengan jarum. Kelompok hewan memilih karton berwarna orange dan hitam. Karton warna hitam digunakan untuk dasar (menutup permukaan karton) dan karton orange dijadikan hiasan di atas karton hitam yang kemudian dibentuk motif badan lebah. Tali plastik digunakan untuk menghiasi pergelangan tangan dan kaki.

Pada sayap lebah, selain diberi hiasan dari kartun berwarna, peserta juga memberikan motif-motif yang bentuk dengan menggunakan spidol. Bentuk motif tersebut berupa garis-garis lengkung yang menyerupai daun paku/pakis, yaitu bergulung pada ujungnya. Selain itu juga peserta membuat motif empat penjuru yang menyerupai bunga pada bagian tengan sayap. Pada sisi belakang sayap diberi karet rok yang berfungsi sebagai media untuk mengaitkan sayap pada tangan anak.

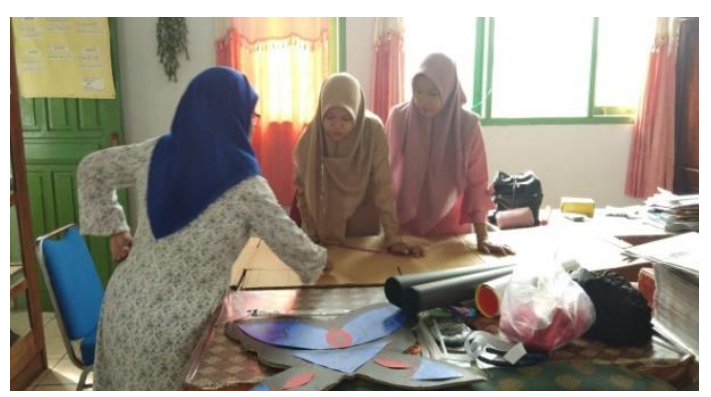

Gambar 3.

Kelompok Tema Hewan Membuat Pola pada Kardus

(Dokumentasi oleh Dwi Anggraini)

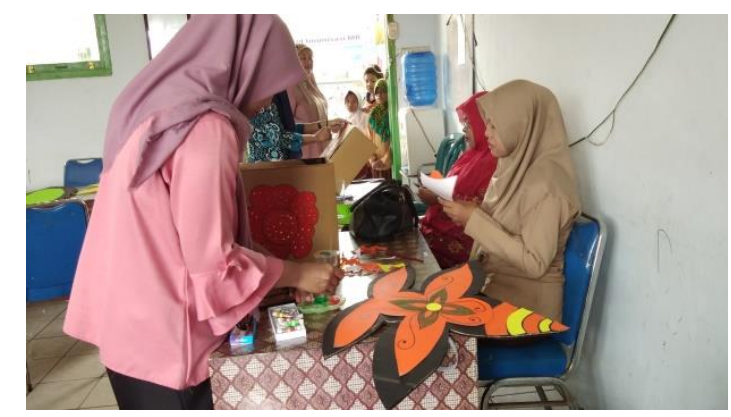

Gambar 4.

Kelompok Tema Hewan Membuat Hiasan pada Rok

(Dokumentasi oleh Dwi Anggraini)

Bagian kepala dibentuk kepala lebah yang dilengkapi dengan mata dan antena lebah. Kepala ini juga dibentuk dari kardus yang kemudian dilapis karton hitam. Bentuk tersebut kemudian ditempelkan pada bando polos. 


\section{Jurnal Batoboh, Vol 4 , No 1, Maret 2019 \\ Hasnawati, Dwi Anggraini, Pebrian Tarmizi}

Kelompok tema hewan menggunakan kardus yang dibentuk menyerupai rok (berbentuk kubus). Rok tersebut diberi gambar bunga raflesia berwarna merah dan daun berwarna hijau, dilengkapi dengan warna lain seperti hijau dan biru untuk memperindah. Pada bagian daun diberi potogan-potongan kertas origami berwarna merah dan biru. Pada bagian rok ini dilengkapi dengan tali plastik yang digunakan sebagai gantungan rok yang dikenakan di pundak.

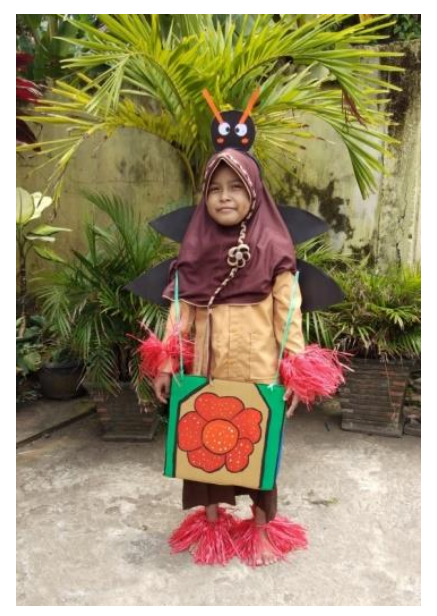

Gambar 5.

Properti tema Hewan Tampak Depan (Dokumentasi oleh Dwi Anggraini)

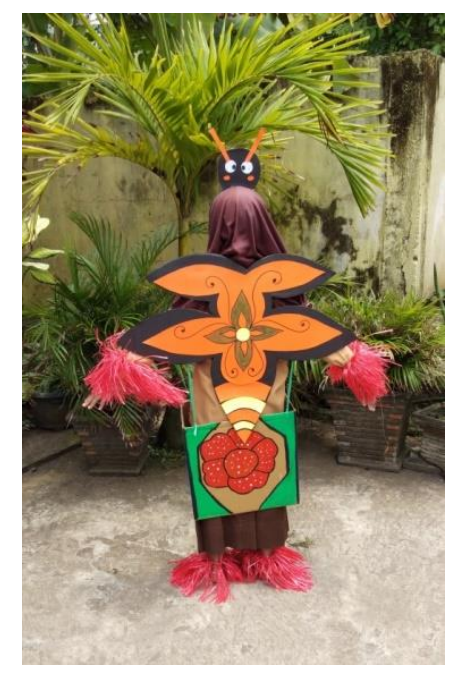

Hal | 38

Gambar 6.

Properti Tema Hewan Tampak Belakang (Dokumentasi Oleh Dwi Anggraini)

\section{b. Deskripsi Pembuatan Properti Tema}

\section{Tumbuhan}

Kelompok kedua adalah kelompok dengan tema tumbuhan. Tumbuhan yang dipilih tidak spesifik pada jenis tumbuhan apa yang dimaksud. Kelompok ini hanya mengambil ciri tumbuhan pada umumnya, seperti adanya daun, kelopak bunga/ bunga, dan pot. Bahan yang dipilih untuk membuat properti tema tumbuhan ini yaitu kardus, bando, karton berwarna (hitam, kuning dan hijau), kertas origami (warna orange dan hijau), cat air, tali plastik warna hijau. Sedangkan alat yang dipilih yaitu lem tembak, gunting dan cutter.

Pertama, salah seorang peserta membuat pola daun yang digunakan seperti sayap. Pola daun yang dibuat di atas kardus kemudian digunting/ dipotong menggunakan pisai cutter, lalu dilapisi 


\section{Jurnal Batoboh, Vol 4 , No 1, Maret 2019 \\ Hasnawati, Dwi Anggraini, Pebrian Tarmizi}

dengan karton hitam. Setelah itu dibuat pola daun dengan guratan tulang daun di atas karton berwarna hijau. Karton hijau ini kemudian ditempelkan pada bagian atas kardus yang telah dilapisi karton hitam tadi.

Untuk bagian kepala, peserta membuat pola kelopak bunga sebanyak lima buah kelopak pada kardus. Kemudian pola itu digunting dan dilapisi oleh karton berwarna kuning. Ketika menempelkan kardus pada karton kuning, pola bagian bawah pada karton kuning dibuat lebih panjang dari ukuran kardus. Fungsinya agar bagian karton yang berlebih dapat dijadikan pengikat atau dijadikan bagian yang dilemkan pada bando. Peserta yang lain membuat hiasan untuk pergelangan kaki dan tangan menggunakan bahan tali plastik berwarna hijau.

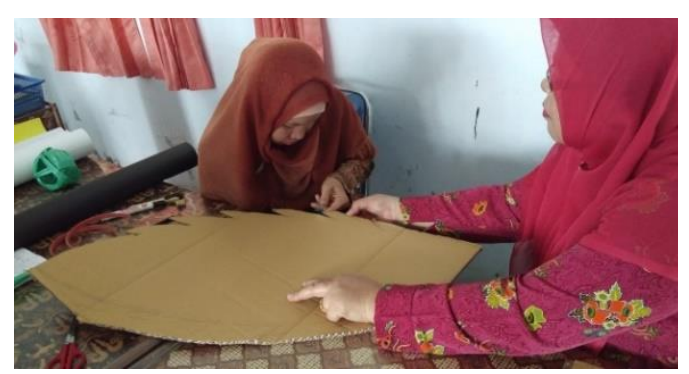

Gambar 7.

Peserta menggunting kardus pola daun (Dokumentasi oleh Dwi Anggraini)

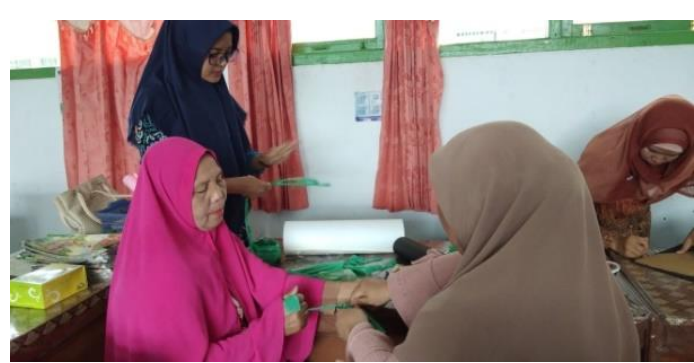

Hal | 39

Gambar 8.

Peserta membuat hiasan tangan dan kaki dari tali plastik berwarna hijau (Dokumentasi oleh Dwi Anggraini)

Sama seperti yang dibuat oleh kelompok hewan, kelompok tumbuhan juga membuat rok dengan menggunakan bahan kardus. Rok yang dibuat berbentuk bujur sangkar. Rok kelompok tumbuhan diberi cat hitam dan dominan berwarna coklat. Kemudian rok ini diberi hiasan guntingan-guntingan kertas origami berwarna hijau dan orange serta guntingan tali plastik berwarna hijau. Rok ini dibuat sebagai pot untuk bunga dan dilengkapi tali plastik pada bagian kiri dan kanannya agar bisa digunakan sebagai kostum, dengan cara menggantungkan tali tersebut pada bahu.

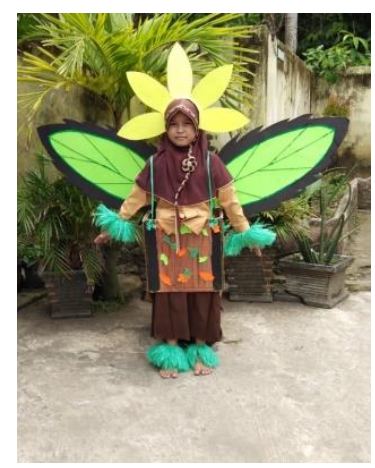

Gambar 9. Properti tema tumbuhan (Dokumentasi oleh Dwi Anggraini) 


\section{Jurnal Batoboh, Vol 4 , No 1, Maret 2019 \\ Hasnawati, Dwi Anggraini, Pebrian Tarmizi}

\section{PEMBAHASAN}

Membuat properti tari dengan memanfaatkan barang bekas merupakan hal yang baru bagi guru SD Negeri 47 Kota Bengkulu. Oleh sebab itu, kegiatan pelatihan ini menjadi hal yang menarik dan menyenangkan bagi peserta sasaran. Semua guru antusias saat menerima materi dan juga praktik membuat properti tari. Hasil properti yang dibuat peserta melebihi ekspektasi tim PPM. Hal ini terlihat dari properti yang dibuat lebih kreatif dan menarik dibandingkan dengan contoh sederhana yang dibuat oleh tim PPM.

Salah satu tujuan dari pelatihan ini yaitu mengurangi limbah, khususnya limbah kardus. Hal ini dikarenakan sekolah ini berada di tengah-tengah pemukiman yang banyak terdapat warung di sekitarnya. Penggunaan kardus untuk membuat properti merupakan upaya untuk menerapkan prinsip 4R (Reduse, Reuse, Recycle, dan Replace). Properti yang dibuat dengan memanfaatkan kardus merupakan properti yang ramah lingkungan, aman dan bahannya dapat dengan mudah ditemukan di sekitar sekolah. Seperti yang dilakukan oleh Sulastri dkk (2017) yaitu timnya mengadakan pelatihan pembuatan alat permainan edukatif (APE) ramah anak bagi guru PAUD di Kota Bandung. Pembuatan APE ini mengusung konsep aman bagi anak, ramah lingkungan dan bersumber dari bahan yang mudah diperoleh dari lingkungan sekitar, biaya pembuatan rendah, serta melaksanakan prinsip $4 R$. Dari kegiatan ini mengubah mindset peserta bahwa membuat APE dapat menggunakan bahan yang ada di lingkungan sekitar dan hanya membutuhkan kreativitas serta inovasi untuk membuatnya. Selain itu, APE yang dibuat terjamin keamanannya karena mengetahui sendiri sumber bahan pembuatannya.

Pemanfaatan limbah kardus dapat dimanfaatkan dalam dunia pendidikan, salah satunya yaitu dengan menggunakannya sebagai sumber bahan utama untuk membuat properti tari. Pemilihan pembuatan properti tari dikarenakan properti merupakan salah satu unsur pendukung di dalam tari, yang mana walaupun hanya sebagai pendukung tetapi juga memiliki arti. Hal ini sejalan dengan pendapat Hasnah (2010) yang mengatakan bahwa properti tari merupakan semua peralatan yang mendukung yang digunakan dalam pementasan tari. Lebih lanjut Meri dalam Hidajat mengatakan bahwa properti merupakan peralatan penunjang gerak sebagai wujud 


\section{Jurnal Batoboh, Vol 4 , No 1, Maret 2019 \\ Hasnawati, Dwi Anggraini, Pebrian Tarmizi}

ekspresi. Kehadiranya bersifat fungsional,

yaitu penggunaannya lebih berorientasi pada kebutuhan tertentu dalam upaya memberikan arti pada gerak atau sebagai tuntutan ekspresi.

Seperti yang telah dijelaskan sebelumnya, bahwa properti memiliki arti penting dalam sebuah tarian. Hal ini sejalan dengan penelitian yang dilakukan oleh Putri dkk (2014), bahwa dalam tari Makan Sirih sirih tidak hanya digunakan sebagai properti, tetapi sirih merupakan bagian dari kehidupan masyarakat Tanjung Batu Kecamatan Kundur Kabupaten Karimun Kepulauan Riau. Sirih bermakna memuliakan dan melambangkan penghormatan. Jika sirih digantikan oleh permen, maka maknanya akan hilang.

Berdasarkan data tersebut, dapat dikatakan bahwa kedudukan properti dalam tari yang menggunakannya sebagai pendukung sangat penting. Keberadaannya tidak dapat digantikan karena terkait dengan makna yang terkandung di dalamnya. Begitupun dengan properti dalam tari bertema untuk anak-anak SD kelas rendah. Keberadaan properti selain merupakan simbol yang mendukung ekspresi tarian, juga sesuai dengan karakteristik anak SD yang senang bermain dan menyukai hal-hal yang menarik.
Properti yang dibuat merupakan properti dengan memadukan berbagai macam warna untuk menarik perhatian siswa agar mau menari, mengingat tidak semua anak menyukai tari terutama anak laki-laki.

Pada properti yang dibuat oleh sasaran, baik tema hewan maupun tema tumbuhan dominan menggunakan garisgaris lengkung. Garis ini memberi kesan lembut dan lentur. Hal ini sejalan dengan pendapat Aminuddin (2009) bahwa garis teriri dari garis lurus yang memberikan kesan tegas dan keras, garis lengkung memberikan kesan lembut dan lentur, serta garis spiral atau pilin memberikan kesan luwes.

Warna-warna yang digunakan dalam membuat properti tari tema hewan dan tumbuhan yaitu kuning, hijau, orange, biru, merah, coklat dan hitam. Warna kuning, biru dan merah tergolong pada warna primer. Sedangkan hijau dan orange merupakan warna sekunder, warna coklat adalah warna tersier, serta hitam merupakan warna netral. Hal ini sejalan dengan teori Brewster dalam Swasty (2010) yang menyatakan bahwa warna-warna yang ada di alam dikelompokkan menjadi warna primer, sekunder, tersier dan warna netral. Warna primer merupakan warna dasar yang tidak dicampur dengan warna 


\section{Jurnal Batoboh, Vol 4 , No 1, Maret 2019 \\ Hasnawati, Dwi Anggraini, Pebrian Tarmizi}

lain. Pigmen warna yang termasuk dalam golongan ini adalah merah, biru dan kuning. Warna sekunder merupakan hasil percampuran dua warna primer dengan perbandingan 1:1 yaitu jingga (campuran warna merah dengan kuning), hijau (campuran warna biru dengan kuning) dan ungu (campuran warna merah dengan biru). Warna tersier merupakan campuran salah satu warna primer dengan salah satu warna sekunder. Contohnya yaitu jingga kekuningan didapat dari percampuran warna kuning dan jingga. Warna indigo (biru keunguan) diperolah dari percampuran warna biru dan ungu. Warna turquoise merupakan campuran warna biru dengan hijau, dan seterusnya. Warna netral merupakan hasil campuran ketiga warna dasar dalam proporsi 1:1:1. Hasil percampuran pigmen warna yang tepat biasanya membentuk warna hitam.

\section{SIMPULAN}

Kegiatan pelatihan pembuatan properti tari dengan memanfaatkan barang bekas membawa dapat yang baik. Berdasarkan kegiatan yang telah dilakukan, peserta pelatihan dapat memiliki keterampilan dalam membuat properti dengan memanfaatkan barang bekas yaitu kardus sebagai bahan utama dan bahan pelengkapnya adalah karton berwarna, kawat, tali plastik, kertas origami, dan cat air. Adapun temuan dalam kegiatan ini adalah guru-guru SD Negeri 47 Kota Bengkulu yang merupakan sasaran kegiatan pelatihan ini dapat lebih kretaif membuat properti. Hal ini ditunjukkan oleh hasil karyanya yang lebih bagus dan lebih menarik dari contoh properti yang dibawa oleh tim PPM.

\section{DAFTAR PUSTAKA}

Badan Standar Nasional Pendidikan (BSNP). (2006). Offline: diunduh 6 Mei 2018.

Hamzah, S. (2013). Pendidikan Lingkungan. Bandung: Refika Aditama

Hasnah. (2010). Pengetahuan Tari. Padangpanjang: Puslit dan P2M ISI Padangpanjang.

Hidajat, R. (2008). Seni Tari: Pengantar Teori dan Praktek Meyusun Tari Bagi Guru. Malang: Jurusan Seni \& Desain Fakultas Sastra Universitas Negeri Malang

Kusumastuti, E. (2009). “Peningkatan Kecerdasan Emosional Anak Usia Dini melalui Pembelajaran Seni Tari" dalam Lembaran Ilmu Kependidikan Jilid 39, No 2, Desember 2009.

Mulyani, N. (2016). Pendidikan Seni Tari Anak Usia Dini. Yogyakarta: Gava Media.

Peraturan Pemerintah RI No 19 Tahun 2005 Tentang Standar Nasional 
Pendidikan . Offline: diunduh 6 Mei 2018.

Putri, M. S., Asriati, A., \& Indrayuda, I. (2014). Makna Sirih Dalam Tari Makan Sirih Di Tanjung Batu

Kecamatan Kundur Kabupaten Karimun Kepulauan Riau. Jurnal Sendratasik, 2(2), 61-70.

Sekarningsih, F. \& Rohayani, H. (2006). Kajian Lanjutan Pembelajaran Tari da Drama I. Bandung: UPI Press.

Sulastri, Y. L., Rahma, A., \& Hakim, L. L. (2017). IbM Pembuatan Alat Permainan Edukatif (APE) Ramah Anak Bagi Guru Paud di Kota Bandung. JURNAL PENGABDIAN KEPADA MASYARAKAT, 7(2), 8491.

Swasty, W. (2010). AZ Warna Interior: Rumah Tinggal. PT Niaga Swadaya. 